\title{
The Study of Biological and Economic Characteristics of Some Imported Walnut Tree Varieties in Conditions of Piedmont Zone in Armenia
}

\author{
G.S. Santrosyan, G.S. Gabrielyan, A.K. Muradyan, L.V. Hovhannisyan \\ Armenian National Agrarian University \\ santros_gagik@mail.ru, gaygabrielyan1978@gmail.com, muraramayis1957@gmail.com, luda.Hovhannisyan@bk.ru
}

\section{A R T I CLE I N F O}

\section{Keywords:}

walnut tree,

semidwarf varieties,

phenological phases,

male and female flowers,

kernel/nucleus yield,

yield capacity,

efficiency

\begin{abstract}
A B S T RA C T
The morphological investigations and yield estimation of some walnut tree varieties have been conducted in the piedmont zone of the RA Ararat valley. It has been disclosed that biological peculiarities of the imported walnut tree varieties Ideal, Chandler and Lara Peral comply with natural and climatic conditions of the piedmont zone in the Ararat valley. They provide growth and development characteristic to the mentioned varieties, and in the 10th to 12th year of the orchard establishment, 3.1-4.3 t/ha yield is produced.
\end{abstract}

\section{Introduction}

Walnut tree is a highly demanded and valuable crop among the fruit tree species. Nowadays, it has a significant production and industrial value in all agricultural zones of the Republic of Armenia.

Currently, in the developed horticultural countries only intensive dwarf and semidwarf orchards are being established (http://agris.fao.org/agris-search/), where the number of trees per the unit area increases in 2-5 times as compared to the traditional orchards. For such kind of orchards highly productive crop varieties have been bred through the selection method.

In the intensive orchards all trees are not only fruitful, but also homegeneous (with the same size and form), without any qualitative changes, which is associated with a number of privileges.

In the recent years, different walnut tree varieties have been imported into Armenia, the biological and economic characteristcs of which per the agricultural zones are not studied yet. So, it is not always feasible for the farmers to cultivate the mentioned crops, but at the same time, opportunity is created to develop and apply efficient cultivation technologies required for a specific variety.

\section{Materials and methods}

The current research aims to study and introduce high yielding, semidwarf, early-season and valuable walnut tree varieties, characterized with cluster fruiting, to the 
production. The activities were implemented in conditions of the Yeghvard, Nor Yerznka and Nor Geghi communities in Kotayk region. The imported walnut varieties Ideal, Chandler and Lara Peral were selected as study objects and a comparative study was carried out.

The tree of Lara Peral is a variety of French origin, it produces yield in the second year and fructifies via lateral part of the branch. The fruits are early-ripening with $34 \mathrm{~mm}$ diameter, they have roundish form, white kernel and thin but hard shell. About 4-5 tons of yield per hectare is produced. The foliage is cup-like, the male flowers bloom at the end of April and the female flowers in the first decade of May. It is susceptible to bacteriosis. The fruit weighs 11-13 grams, at the initial fruiting stage $12 \mathrm{~kg}$ yield per tree is produced, while at the age of 8 years, that is, in the abundant yield production period, it amounts to $19 \mathrm{~kg}$. It is a tree of average growth with 5-6 m height (Firsov et all., 2015, http://agris.fao.org/ agris-search/, http://www.tandfonline.com/).

The tree of Ideal is a variety of Uzbek origin with 4-5 meters height. It is a semidwarf tree, resistant towards the chlorosis, produces fruits starting from the second year and yields abundantly in the 5 th year. Its fruit is large, oval with thin shell (Firsov et all., 2015, http://agris.fao.org/ agris-search, http://www.tandfonline.com/).

Chandler is a medium-sized walnut variety of American origin with 5-6 meters height; it is a high-yielding, lateral fruit-bearing tree; the fruit weighs $14-16$ grams and it is a mid-ripening variety. The pollinizer is the Franquette variety (Firsov et all., 2015, http://agris.fao.org/agrissearch/, http://www.tandfonline.com/). The Ideal and Chandler varieties are relatively adapted to the Armenian climatic conditions.

The observations were conducted during 2015-2016 years. The experiment was set up in 3 replications and 5 trees per each replication were registered. The transitional process of varietal phenophases was investigated and the yield estimation was conducted according to the universal method developed by All-Russian Scientific Research Institute of Horticulture named after I.V. Michurin (1973) (Yesayan, 1984).

The yield data were subjected to statistical analysis through the method of dispersion analysis. The kernel/nucleus yield of the fruit was determined per 1000 gram fruit through weighing method. To determine the economic efficiency of the walnut varieties recommended for the production, the total money investments and received incomes were taken into account.

\section{Results and discussions}

The walnut varieties investigated by our research group belong to an individual group, which are characterized by botryoidal or spiked fruiting. They develop female flowers and fruits not only from the apex of that year shoots, but also from the lateral fruit buds. In the former case botryoidal, long floriferous shoot from the apical bud is developed, which produces 5-10-15 and more fruits, and in the latter case throughout the whole length of that year shoot up to its bottom part, 1-2 female flowers burst out from each bud, which get well pollinated and produce fruits. Such type of shoots also develop male flowers (Trusheva, 2014). So, self-pollination takes place, due to which they are called self-pollinating nut trees distinguished by sustainable annual fertility.

The transitional process of phenophases per years for the studied varieties is introduced in Table 1.

The results of Table 1 indicate that in the investigated walnut tree varieties defoliation starts late, while the vegetation is lingering and long-lasting. Maximum vegetation period was observed in the Chandler variety (193-200 days per years) and in the variety of Lara Peral it was 184-185 days, that is, the vegetation in this option ends up earlier.

Table 1. Developmental stages of vegetative buds in walnut tree*

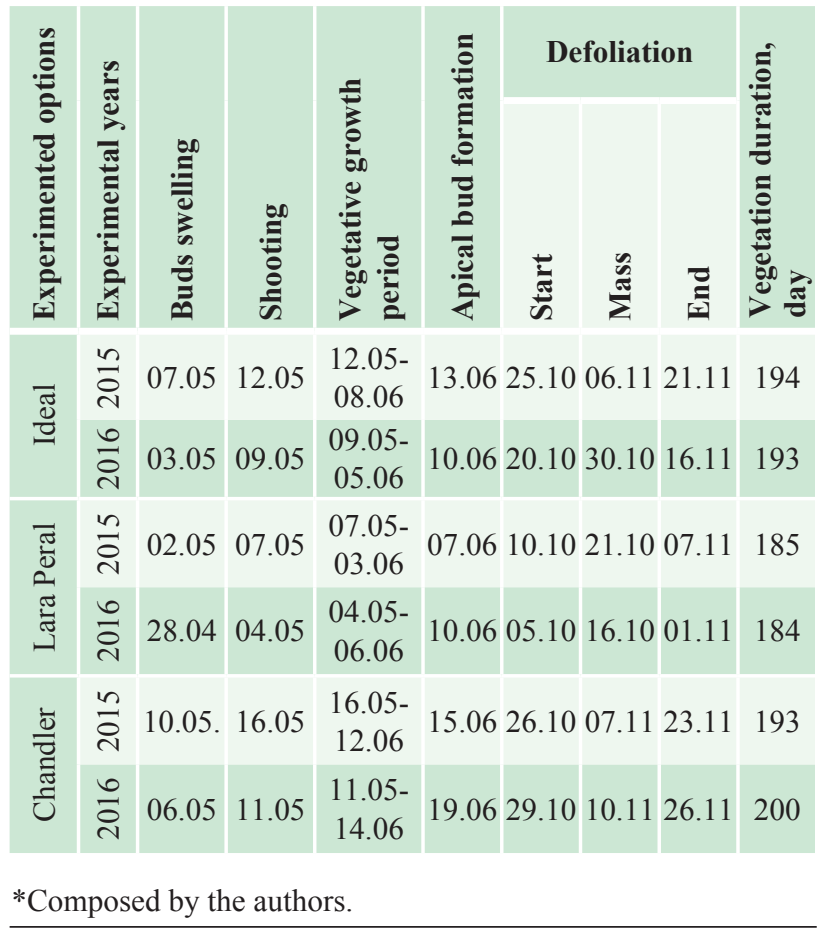


The results summed up in Table 2 disclose that all varieties are mid-ripening; the earliest mass blooming stage (May 25-30) is observed in the Lara Peral variety and the latest one (1st and 2nd decades of June) is recorded in the Ideal and Chandler varieties. The analysis of the table data testify that Lara Peral is an early mid-ripening variety, while the Ideal and Chandler varieties are mid-ripening tree varieties.

Table 2. Changes of walnut tree generative buds on the current-year shoots*

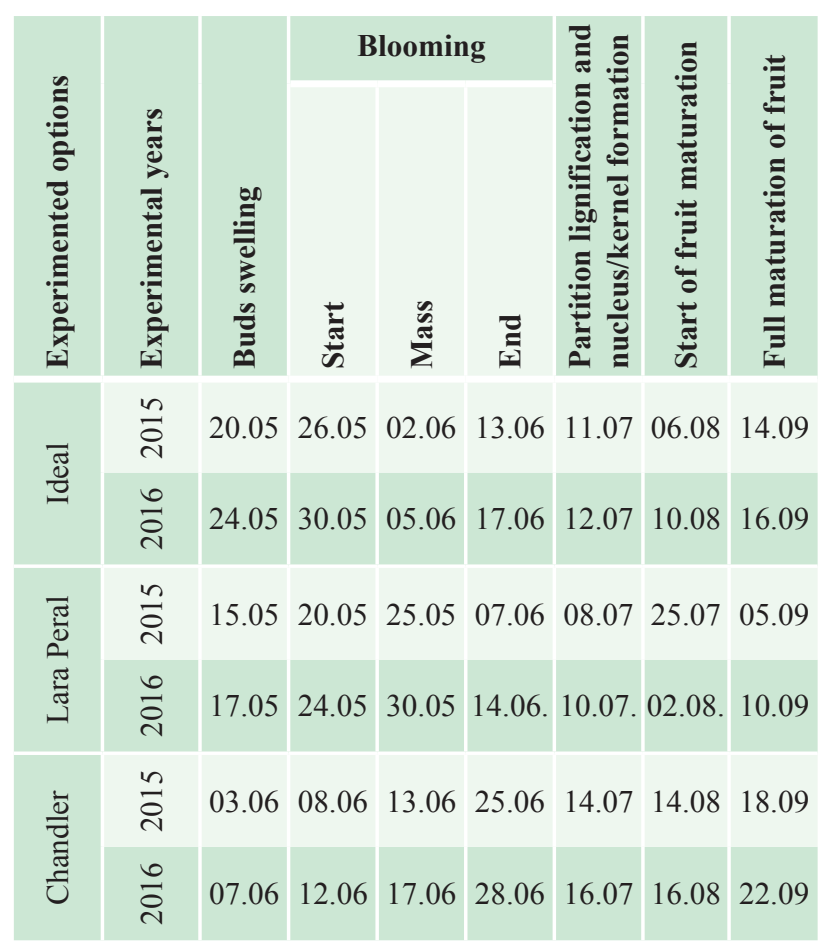

*Composed by the authors.

Any varietal study is aimed at the selection of highquality and high-yielding varieties. The results of the yield capacity for the varieties studied in the current research work are introduced in Table 3 . The table data show that 333 walnut trees with $6 \times 5 \mathrm{~m}^{2}$ feeding area are planted per land hectare.

The fruits of investigated varieties have thin shell and the kernel is easily removed from the lignified stratum. The fruit of Lara Peral is roundish with pointed edge and the kernel is white, while in Ideal and Chandler varieties it is longish with yellow kernel. The variety of Ideal provides high kernel yield (50-55 \%). Chandler and Ideal varieties are distinguished by high yield capacity per hectare providing 3.9-4.2 t/ha yield.
Table 3. Yield capacity indices in the walnut tree varieties*

\begin{tabular}{|c|c|c|c|c|c|}
\hline 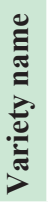 & 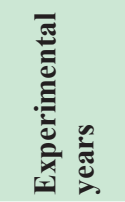 & $\begin{array}{c}\text { Average } \\
\text { fruit weight } \\
\text { /without } \\
\text { green husk/, } \\
\text { gram }\end{array}$ & $\begin{array}{c}\text { The ratio } \\
\text { of kernel } \\
\text { and fruit, } \\
\%\end{array}$ & $\begin{array}{c}\text { Yield } \\
\text { capacity, } \\
\text { kg/tree }\end{array}$ & $\begin{array}{c}\text { Yield } \\
\text { capacity, } \\
\text { t/ha }\end{array}$ \\
\hline \multirow{3}{*}{$\begin{array}{l}\overline{\mathbb{J}} \\
\bar{D}\end{array}$} & 2015 & 16.0 & \multirow{3}{*}{$50-55$} & 13.0 & 4.3 \\
\hline & 2016 & 15.3 & & 12.5 & 4.2 \\
\hline & Average & 15.6 & & 12.7 & 4.2 \\
\hline \multirow{3}{*}{ 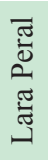 } & 2015 & 12.6 & \multirow{3}{*}{$49-50$} & 9.6 & 3.2 \\
\hline & 2016 & 12.0 & & 9.5 & 3.1 \\
\hline & Average & 12.3 & & 9.5 & 3.1 \\
\hline \multirow{3}{*}{ 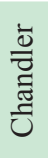 } & 2015 & 12.0 & \multirow{3}{*}{$45-50$} & 12.0 & 4.0 \\
\hline & 2016 & 13.3 & & 11.3 & 3.8 \\
\hline & Average & 12.6 & & 11.6 & 3.9 \\
\hline
\end{tabular}

*Composed by the authors.

The results of yield capacity were subjected to statistical analysis through the dispersion method; LSD $0.95=0.78 \mathrm{t} / \mathrm{ha}, \mathrm{Ex} \%=5.9$.

The data of Table 4 indicate that the production of fruits of Chandler and Ideal variety is economically efficient; the extra profit for these options have amounted to 1125.0 and 1345.0 thousand AMD respectively. The extra yield in the Ideal and Chandler varieties have made $11.0 \mathrm{c} / \mathrm{ha}$ and $8 \mathrm{c} /$ ha respectively.

Estimation of the economic efficiency enables to sum up the results of varietal studies (Table 4).

Table. 4. Estimation of economic efficiency in walnut tree varieties*

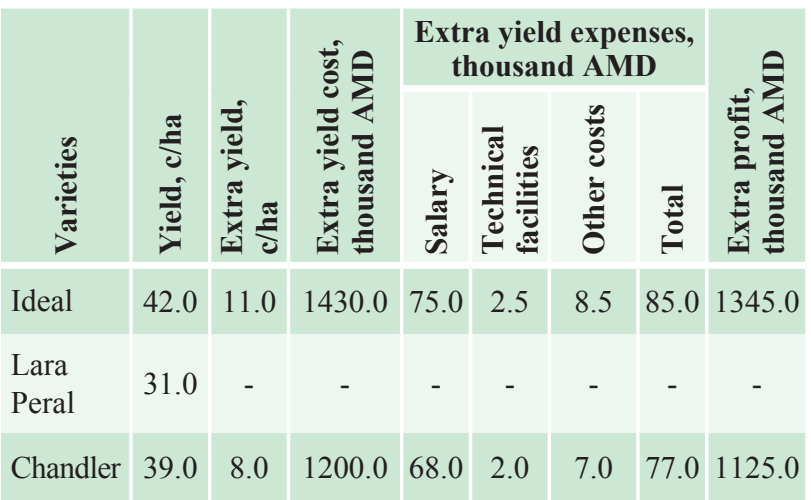

*Composed by the authors. 


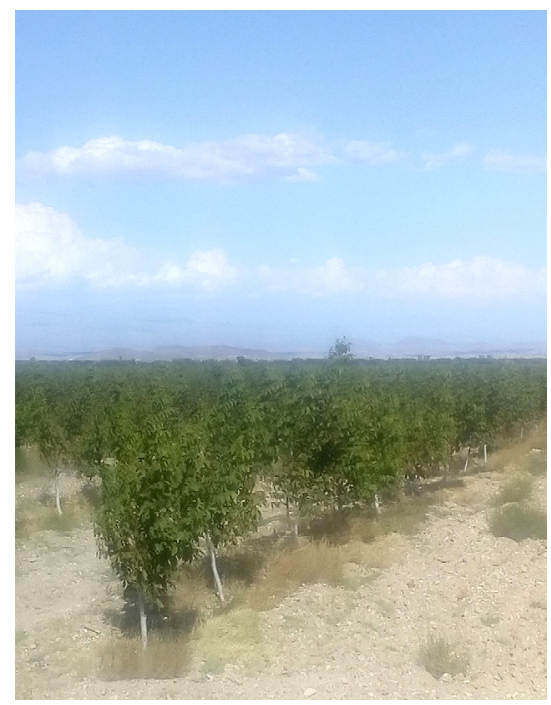

Figure.

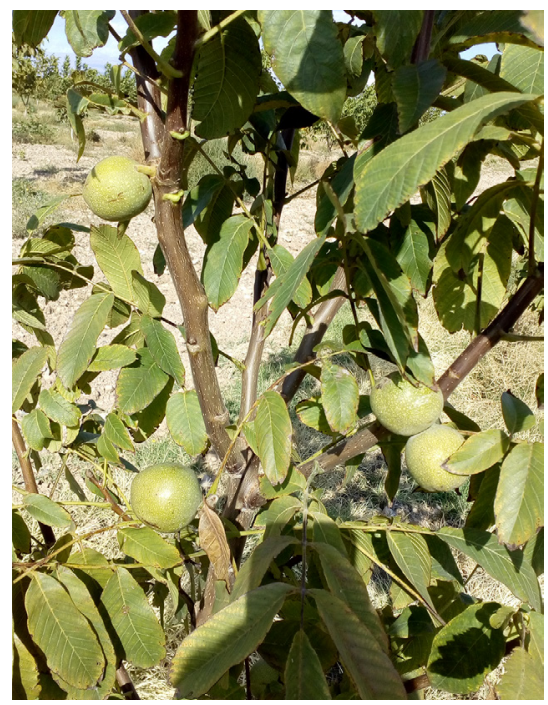

Fertile branch

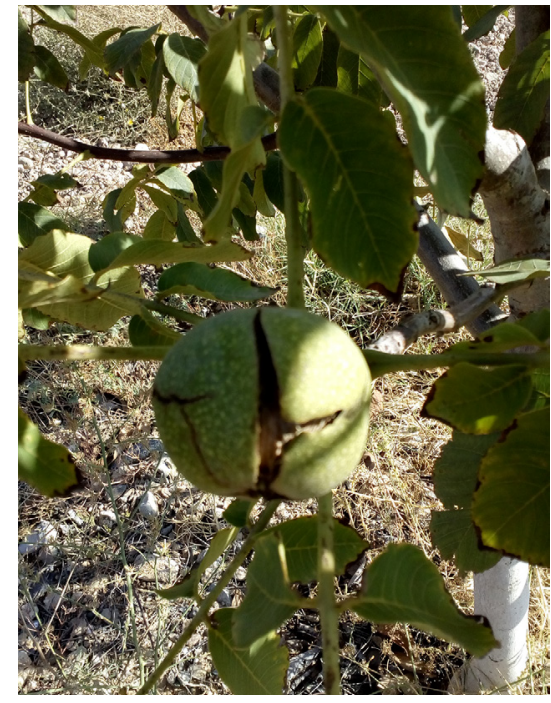

Mature fruit.
Walnut orchard and fertile branches are introduced in the relevant figure.

\section{Conclusion}

Based on the obtained results all the mentioned three varieties are recommended to the production for their further cultivation. They are all distinguished by botryoidal fruiting; besides, they are all semidwarf, early-season tree varieties with high yield capacity and are highly demanded in the market.

\section{References}

1. Firsov, G., Vasilyev N., Fedorova, N. (2015). Komarov Botanical Institute RAS. Species of Juglandaceae at
Peter the Great Botanic Garden at Apothecaries Island.

2. http://agris.fao.org/agris-search/ (accessed on 18.08.2021).

3. http://www.tandfonline.com/ (accessed on 20.09.2021).

4. Program and Methodology for the Study of Varieties of Fruit, Berry and Nut Crops. - Michurinsk, 1973. - 493 p. (Ministry of Agriculture of the USSR. AllRussian Scientific Research Institute of Horticulture named after IV Michurin).

5. Trusheva, N.A. (2014). Study of the Growth and Development Dynamics of the Walnut Fruit in the Moscow State Institute of Technology, Maykop (in Russian).

6. Yesayan, G.S. (1984). Walnut Cultivation, Yerevan, $-67 \mathrm{p}$. 